\title{
What is Strategic Project Leadership?
}

\author{
Aaron Shenhar ${ }^{*}$
}

\author{
The SPL Group, 1 Claridge Dr. Suite 227, Verona, NJ 07044, USA
}

\begin{abstract}
As project management is becoming more strategic and business oriented, new and formal approaches are needed to address the changes in the profession. Strategic Project Leadership ${ }^{\mathbb{B} 1}$ (SPL) is a comprehensive, research-based approach to project management. It combines the strategic, business-related aspects of projects, the need to adapt a project to its unique level of innovation and context, the leadership perspective of inspiring and motivating the team, and the traditional needs of getting the job done. The main objective of SPL is to inspire project managers to be the business leaders of their projects and is giving them the tools to do that. In their new leadership role, they must deal with the strategic and business aspects of their projects, articulate a vision to inspire and motivate their teams, and learn how to adapt their management style to the right project and environmental context. This integrated, research-based, and industry-proven approach addresses the reality that most projects today are uncertain, complex, non-linear, and changing; and they must be managed in a dynamic and flexible way while, "one size does not fit all." More important, it acknowledges the fact that meeting the 'triple constraint' of time, budget, and performance goals is insufficient to guarantee business success. Successful projects today require, in addition, the strategic and leadership perspectives, as well as considering the specific impact of innovation on each project. This paper starts by describing the shortcomings of traditional project management and addressing the context for building the SPL approach; it then outlines its major concepts, planning components, and managerial implications.
\end{abstract}

Keywords: Innovation, project management, project spirit, project strategy, science and art of project management, strategic project leadership.

\section{INTRODUCTION}

Perhaps the most critical element in the competitiveness and growth of organizations is project management (PM). Clearly, no organization can survive today without projects. Projects are the engines that drive innovation and change; they turn ideas and strategy into new products and services, and they make organizations better, stronger, and more competitive. Furthermore, in an increasingly dynamic and competitive world, the investment and effort in projects continue to grow.

However, in spite of the growing importance of projects and consequently, the increased investment in education and certification programs, most projects today are still showing poor performance. Most projects don't meet their time and budget goals, and many do not deliver their expected business returns. In fact, new research recently suggested that project success is actually going down, not up [1], perhaps due to increased complexity, higher pace, and accelerated technological changes.

Paradoxically, however, organizations are often not seeing project management as a strategic competitive asset,

\footnotetext{
*Address correspondence to this author at the The SPL Group, 1 Claridge Dr. Suite 227, Verona, NJ 07044, USA; Tel: 201-323-3246;

E-mail: ashenhar@splwin.com

${ }^{1}$ Trademark Note: Strategic Project Leadership ${ }^{\circledR}$ is a trademark of Aaron Shenhar and the SPL Group. It is free to use for academic education and research purposes, as well as writing and discussion. It cannot be used for commercial purposes without written permission from the author.
}

and many CEOs perceive PM as simple, straightforward, and just operational. The rare combination of importance, weakness, and neglect, provides a unique opportunity for companies and executives to make a difference, and benefit from turning project management into a powerful competitive activity.

In this paper we describe the status of conventional project management and the opportunity for change. We will introduce the concept of Strategic Project Leadership, which was developed during years of research, consulting, and teaching, in order to help organizations and managers make this evolution. We will start by analyzing the reasons for weaknesses in the profession, present our research process and findings, and provide the framework for turning projects into powerful competitive assets. We conclude by describing a set of managerial implications and principles on how to implement SPL on top of the existing project management organizational practices.

\section{WHY IS PROJECT MANAGEMENT STILL WEAK?}

Many organizations today are using a well-established approach and a set of universal techniques to manage their projects; yet they often find out that the traditional approach to project management is insufficient to deal with today's dynamic business requirements. In fact, the truth is that even if you do everything by the book and precisely follow all the formal guidelines of PM, your project may still fail! The question is, why? And what is missing? 
The traditional approach to project management is based on concepts that were established about 50 years ago. These concepts suggest that a project consists of a collection of activities that need to be planned and executed according to a predetermined plan, while the goal of the project is essentially to deliver time, cost, and scope goals - what has become known as the "Triple Constraint." Following these concepts, the discipline of project management has developed standard tools and applications such as Work Breakdown Structures (WBS), Network Diagramming Techniques, Critical Path, Gantt Charts, Earned Value, Critical Chain, etc., mostly built for planning and managing the project in the most efficient way, namely to help meet the triple constraint.

In spite of dramatic technological development and accelerated learning in science, the project management discipline has not changed much over the years. The same basic concepts are still dominating the profession today. We believe it is time to face the new realities of business and organizations and advance project management to the next level, which will address these realities.

Many authors have discussed in recent years the reasons why the classical approach is insufficient [2, 3]. Two influential studies by Williams [4] and Lenfile and Loch [5] have demonstrated specific shortcomings such as, sticking to an operational view based on the triple constraint, or the focus on excessive control of process, while neglecting to deal with uncertainty and change.

As Shenhar and Dvir [6] have shown, first of all, the conventional approach to project management is based on a predictable, fixed, relatively simple, and certain model. Furthermore, it is often decoupled from dynamic changes in markets, technology, or business environments. However, most projects today are unpredictable, changing, and involving a great deal of uncertainty and complexity. In addition, the current guidelines essentially treat all projects in the same way, and use a "one size fits all" approach. In reality, there are significant differences among projects and "one size does not fit all." To succeed, project teams must recognize the differences that exist among projects and adapt their style to the specific project characteristics and context. Even agile project management (which was developed recently, mostly for software projects), is dealing with on going changes and adjustments during development, but does not address differences among projects and does not show how to adapt project management to a specific project environment.

Second, while almost all project launches are motivated by a business need or opportunity, the current project management approach is not designed to deal formally with the business side, focusing, as we mentioned, just on operational efficiency. The reality is that achieving the triple constraint is insufficient. It is only one aspect in a project's success. Research shows that even if projects meet their time and budget goals, they may still end up in disappointing business results [6]; and often even late and costly projects turn out to become tremendous business successes. The real success of a project rests on meeting the business objectives that were determined when the project was conceived $[7,8]$. So if projects are started for business needs and expected results, why should they be managed just to meet time and budget goals? While many practitioners understand this paradox, it is not addressed by the formal traditional project management discipline. A more strategic and businessfocused approach is needed.

Finally, and perhaps most important, traditional project management is looking at the operational part of planning and execution. But it is teams and people, not plans, that make projects successful, and managing a team requires more than just planning and controlling. To do their best work, team members must be motivated and inspired. This requires the project manager to act as a leader, who knows how to define a project's vision and understand how to inspire and motivate his or her team. The traditional approach essentially ignored the role of leadership, assuming that only top executives are those that deal with vision and inspiration. Yet, according to research, the best teams often report that what made the difference was the vision and team's spirit and not rewards or level of pay.

\section{THE ART AND SCIENCE OF PROJECT MANAGEMENT}

The conventional tools of project management provide a universal formal part of the profession - the "mechanics" or the "science." Like in any profession, the science part is practiced around the world in a universal way and shared by professional associations (such as the Project Management Institute $\mathrm{PMI}^{\circledR}$ ) - as well as dozens of consulting groups who offer training and applications based on the classical concepts. But project management is also an art. The art part is not described in books or formal applications. It includes those aspects that are driven by personal experience and creativity of individual leaders. As we have seen in our research on over 600 projects, most of the reasons why projects succeed or fail today belong to the unwritten rules of the profession - the art part. The ratio is often perceived to be $20 \%$ science and $80 \%$ art. The art part includes many of the "weak spots" that were mentioned above, such as dealing with change, adapting to a specific context, and the lack of business focus during project execution (see Fig. 1). Ironically, however, it seems that project teams spend most of their time on the science structured parts, and only a small portion on the art parts [5].

We believe it is time to turn some of the critical elements in the "art part" into science and make them more accessible to project teams in a formal way. If we could teach project teams how to deal in a formal, structured way with change, adaptation, complexity, and business focus, project and organizational results will see substantial improvement.

Another retrospective study identified the seven most common factors to highly successful projects - called "Great Projects" [9] - see Table $\mathbf{1}$.

As can be seen, the seven elements could be grouped into three major groups:

- $\quad$ Business \& Value Focus

- Adapting to Dynamic Innovation

- Inspirational Leadership 


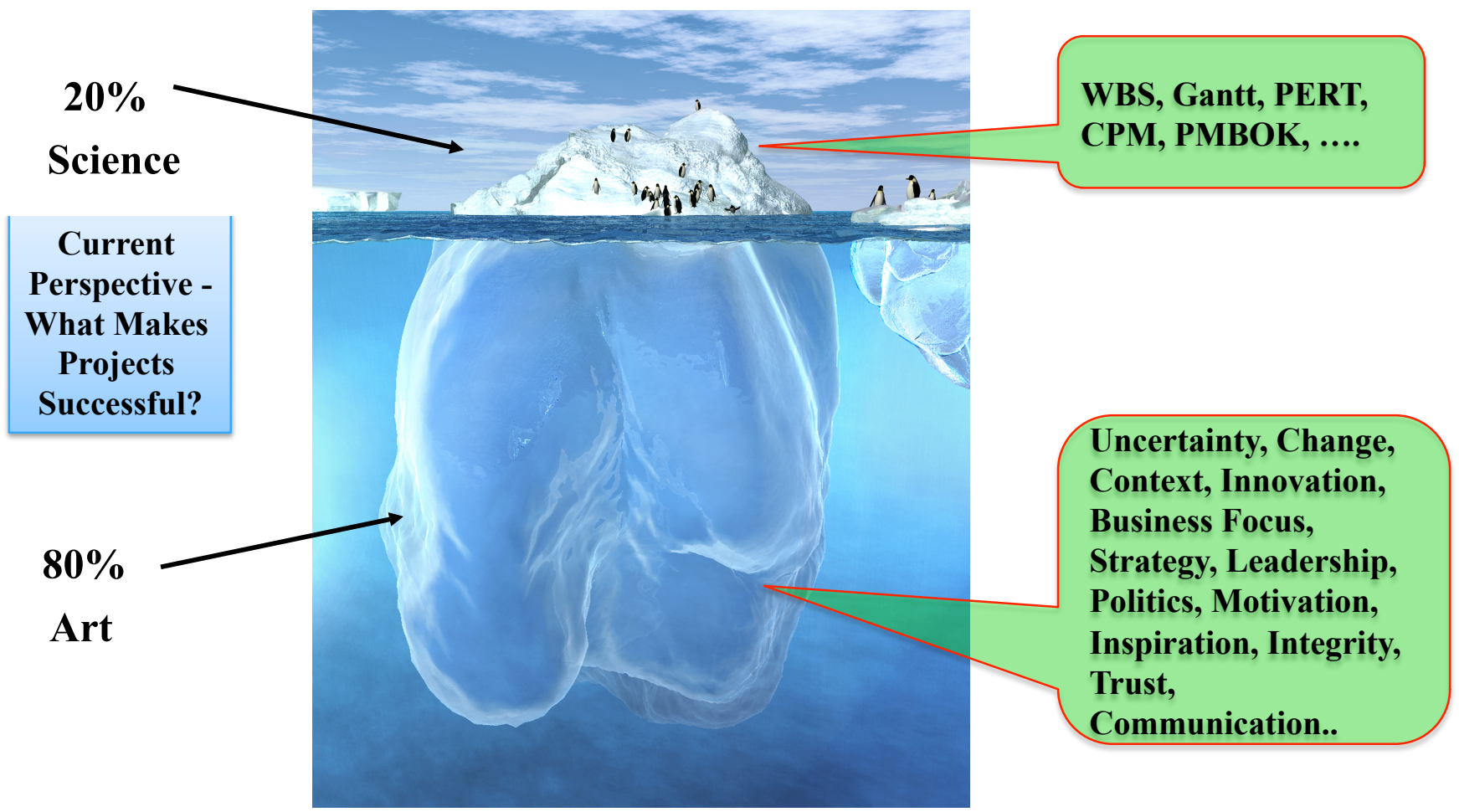

Fig. (1). The art and science of project management.

Ironically, however, traditional project management frameworks are rarely addressing any of these topics. This observation motivated the development of Strategic Project Leadership $^{\circledR}$ (SPL), which was designed as add on to traditional project management. By adding the formal missing components, the goal of SPL was to turn some of the art parts into science. It is important to note that SPL is not discarding or eliminating any of the traditional building blocks. Rather, it builds on the same foundations and using the fundamental tools and frameworks of the PM profession such as WBS and schedules. SPL is adding, however, three important components, as detailed below.

\section{THE CONCEPT AND STRUCTURE OF STRATEGIC PROJECT LEADERSHIP ${ }^{\circledR}$}

Strategic Project Leadership ${ }^{\circledR}$ is based on a simple principle: Expanding the focus of project teams from the project's output, that is, delivering the product on time and budget, to the outcome of the project, that is, the value created by the product, the business results, and the benefits to all stakeholders. Thus, instead of seeing project managers as responsible for "getting the job done," (i.e., completing the project on time and budget, and meeting requirements), SPL transforms project managers into the business leaders of their projects, who are responsible, not only for getting the job done, but also for achieving the business results, and for inspiring and motivating the project team. They are also expected to adapt their style to the right context and innovation, and manage their project in a dynamic and flexible way. In other words, the main objective of Strategic Project Leadership ${ }^{\circledR}$ is to focus a project's activity on business results by creating value, competitive advantage, and winning in the marketplace. SPL combines the operational needs of getting the job done, the strategic, business-related aspects of projects, the need to adapt projects to innovation and context, and the leadership sides of inspiring and motivating the project team.

Table 1. The Common Elements of Great Projects [9].

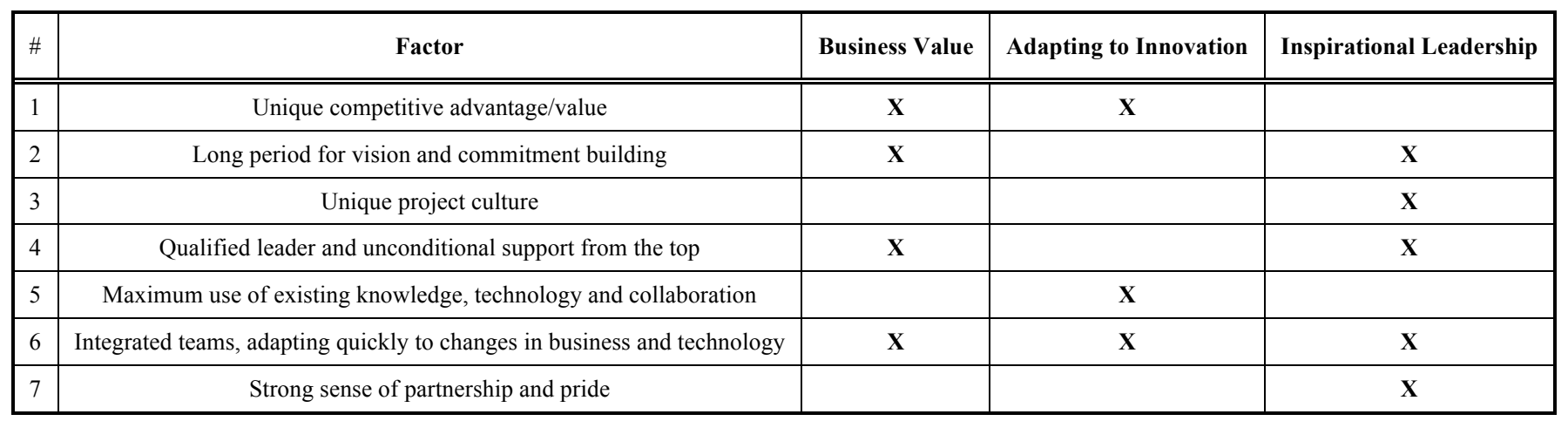


Exhibit 2 describes the additional topics offered by SPL on top of the traditional approach. The first component is the Business-Focus level, which addresses the strategic and business related plans and activities needed to achieve the business results of the project (Fig. 2). In the next sections we describe these components in more detail and briefly discuss project planning and implementation according to SPL. The second addition is called Dynamic Innovation. This part addresses the need to adapt project management to the specific project context and characteristics and to see change as a normal way of life in the modern project management world. The third level deals with Inspirational Leadership. This level deals with the soft sides of project leadership, which needs to develop a unique project vision and spirit of excitement and motivation.

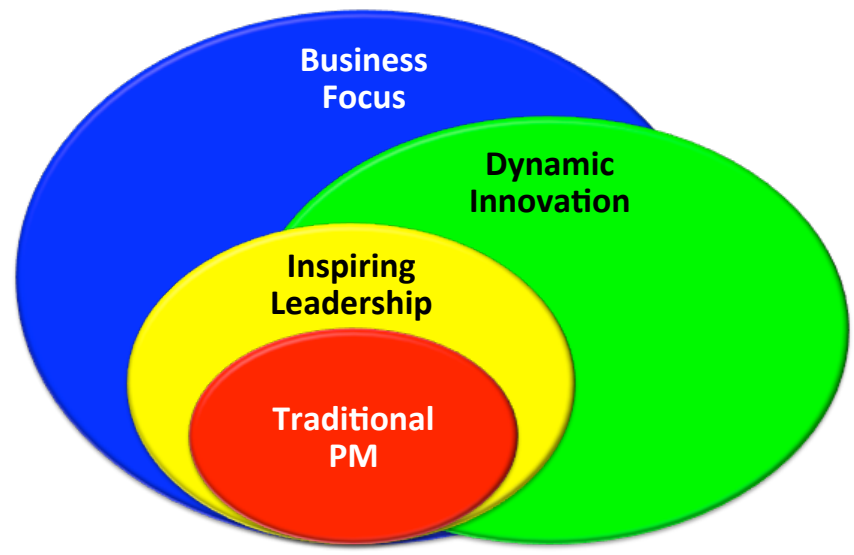

Fig. (2). SPL - The new science of project management.

\section{BUSINESS FOCUS}

\section{A New Model for Planning and Assessing Project Success}

The first step in describing the business focus strategic approach is to address the issue of project success. We suggest that organizations adopt a multi-dimensional framework for planning and assessing project success, instead of the traditional "Triple Constraint." Such framework will become part of the initial plan; it will set the expectations in advance, and be used later as a benchmark for execution, to monitor if the project is still achieving such expectations. The project success framework includes at least five dimensions $[6,10]$ :

- $\quad$ Efficiency - Meeting time and budget goals

- Impact on the Customer - Satisfaction, improvement, loyalty

- Impact on the Team - Growth, satisfaction, retention, morale

- $\quad$ Business Results - Market share, profit, growth

- $\quad$ Preparing the Future - Future technology, new market, capabilities

This framework suggests that you should look at success with a long-term perspective, and beyond immediate efficiency metrics. For example, when Sydney Opera House was built, no one could imagine that the project will take 16 years instead of 7 , and cost $\$ 100 \mathrm{M}$ instead of $\$ 7 \mathrm{M}$. From a traditional success perspective this was a failed project. Today, however, the Opera House stands out as one of the greatest tourist attractions in the world and is considered an on-going success story for Australia and the city of Sydney. No company would agree today to have a similar project experience, but the story suggests that project success should be seen as a multidimensional, time-dependent concept, and must often be considered with a longer-term perspective in mind. Project efficiency is not always the only or even best criteria for success.

The U.S. Space Shuttle Program is another example demonstrating that short-term savings may result in longterm unexpected and unprecedented costs [11]. In an effort to save cost, NASA was restrained in the 1970s into a development contract of $\$ 5 \mathrm{~B}$ instead of a required budget of $\$ 8-10 \mathrm{~B}$, forcing the agency to compromise on development efforts. It had to eliminate its plans for extended technology tests and later design freeze than those required under the restrained budget. The Shuttle's original goal was enable the U.S. affordable space flights on a first-ever-built reusable vehicle. The compromised short-term efficiency gains resulted, however, in an enormous operational cost of \$175B during four decades of Shuttle flights, (not to mention two terrible accidents, which claimed the lives of 14 astronauts). The cost of each flight was $\$ 1.5 \mathrm{~B}$, and maintaining the Shuttle program, added each year $\$ 3.5 \mathrm{~B}$ to NASA's budget. These extended costs led eventually to the retirement of the Shuttle, leaving the U.S. without an ability to reach space on its own. Had the program been seen with a longer-term success perspective, it may well be that the result would have been different and much more positive [11].

The Shuttle experience may exemplify comparable situations today, when complex programs are being forced to achieve short-term savings and are bound by similar constraints. Such programs are often facing tremendous uncertainty and challenges, which are sometimes impossible to be assessed upfront. The typical, financial model of efficiency metrics, often expressed by accounting requests for precise estimates, may not fit the new world of rapid change and high uncertainty. A better approach is to plan such programs with enough contingency funds based on assessing initial levels of program uncertainty, and combine them with incentives to developers for not using all such funds. Our later discussion on adaptation will address this point from another perspective.

\section{Project Strategy - The Missing Link}

Typically, project execution starts after a project plan is created [12]. The plan normally includes the project scope, deliveries, milestones, resources, and activities for execution. Yet, most projects are initiated as part of the company's business strategy and they need to support this strategy. Traditional books and training are often not guiding teams on how to do it, leaving them to come up with their own ways. As we found, in order to translate the company's strategy to what needs to be done on the project in support this strategy, we recommend adding a formal project strategy document between the top-level business strategy and the project plan - we call it "the missing link." But what exactly is project strategy and what does it involve? 
In today's environment, any project outcome - a product, a process, or service - is likely to face competition. Thus, for each of product or service one should ask, how would it stand out? How would it succeed in the face of competition, and what would be its competitive advantage? Project management therefore, should not just be about meeting time and budget goals. It should be about creating competitive advantage and value. A good project strategy document must define how to create the best competitive advantage for winning in the market place. Hence the project strategy is the project's unique way of making this happen. This way should involve the project's approach, direction, and a path that is planned in order to win over the competition [13].

We define a project strategy as: the project perspective, position, and guidelines on what to do and how to do it, to achieve the highest competitive advantage and the best value from the project outcome $[14,15]$. A typical project strategy document will include the following components:

- $\quad$ Background and Opportunity - Why are we doing this project

- $\quad$ Business Objective - What do we want to achieve the outcome

- $\quad$ Product Definition - What is the project creating the output

- $\quad$ Project Definition - How are we going to do it

- $\quad$ Success/Failure Criteria - How will we assess success or failure

- Strategic Concept - The major basis for differentiation, the edge

- Competitive Advantage/Value - Specific drivers of competitiveness

\section{- $\quad$ Strategic Focus - What will the team do}

A famous example to illustrate the concept of project strategy is Apple's project of building the iPod product line and iTunes store in the early 2000s. Apple was not the first company to introduce MP3 players. At that time earlier generations of players were already in the market. Apple, however, saw this as an opportunity to establish leadership in a new sector, integrating the concept of outstanding platform design with an on-line store. Using its competitive advantage of easy-to-use cool products, with easy and immediate access to on-line downloads of music; Apple established itself as an undisputed market leader in this territory. Its strategic focus has always been on uncompromised customer experience and meticulous attention to detail, without worrying too much about cost. The assumption was that great, uncompromised products would later create higher profits and market value. In retrospect, there is no question that the strategic approach that Apple used for the iPod development and introduction, served it well for its next successful products such as iPhone and iPad.

\section{DYNAMIC INNOVATION}

Managers and executives of projects must learn to expect change, and even embrace it. They must accept the reality that almost all their projects will undergo changes, and treat this as the normal way, rather than an exception. Planning should be seen as an on-going process, and re-planning should become common, not exceptional. Teams should use a flexible style of decision-making and employ a "rolling wave of planning" [6], or an "agile project management style" - understanding that not everything can be planned in advance. Changes and adjustments should be added as more information is collected and as the project moves on. And teams should also see this as an opportunity to redirecting the project toward maximizing end results revenues.

\section{The Diamond of Innovation Model for Project Adaptation}

Organizations should understand that "one size does not fit all projects" [16]. They should use frameworks that will help them distinguish between different project types, and adapt project management style to the right project. For example, projects should adapt to different levels of market, technology, and environmental uncertainties; different levels of complexity; or different constraints and limitations. They must also adjust the project to the unique business environment and industry. Shenhar and Dvir's Diamond of Innovation Model [6] offers a framework for analyzing a project's specific context and selecting the right style. The model includes the four dimensions of Novelty, Technology, Complexity, and Pace - see Fig. (3). Each dimension is divided into four different project types, and has a different impact on project management:

- $\quad$ Novelty - How new is the product to your market and users. Novelty represents the level of market uncertainty and it impacts the effort and time it takes to clearly define the product's requirements. Novelty is divided into the following types:

o Derivative, Platform, New-to-the-Market, Newto-the-World

- Technology - How much new technology is used. Technology represents the level of technological uncertainty and it impacts the number of design cycles needed and the time it takes before design freeze. Technology has the following levels:

○ Low-tech, Medium-tech, High-tech, Super Hightech

- Complexity - How complex is the product or the project organization. Complexity depends on the size and complexity of the product and the organization required to complete it. Complexity impacts the degree of formality and coordination needed to effectively manage the project. It has the following levels:

- Material/Component, Assembly/Subsystem, System, Array/System of Systems

- Pace - How critical is your time frame. Pace represents the urgency to complete the project. It impacts the time management and autonomy of the project management team. It has the following levels:

- Regular, Fast/Competitive, Time-Critical, Blitz

A unique Project Diamond describes each project context, and the specific project diamond levels determine 
what is the appropriate style for this particular project. The Project Diamond can also help analyze project difficulties and put a troubled project back on track.

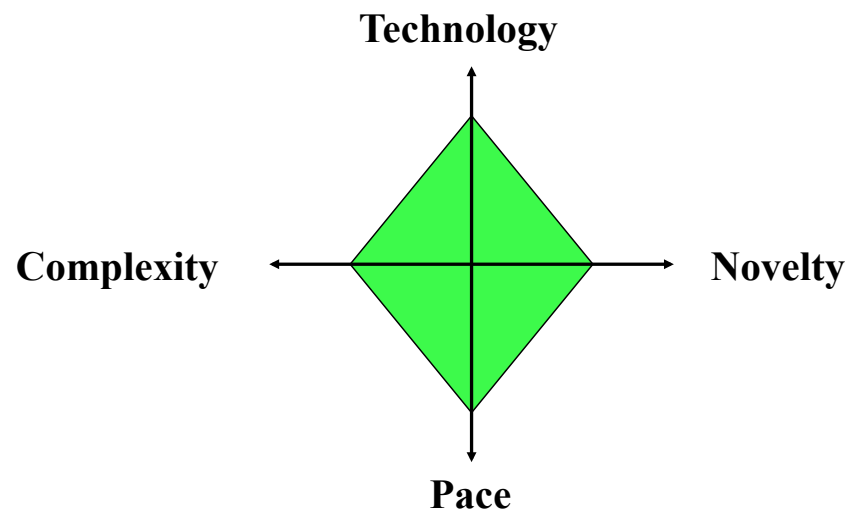

Fig. (3). The diamond of innovation.

The Space Shuttle program mentioned earlier demonstrates how a wrong style may impact the success of a project. Due to budget limitations, the Shuttle was bound to freeze its design, configuration, and technology too early to what the program's uncertainty required. The result was a non-optimal use of technology and a costly program to operate. Specifically, looking at the Diamond's technology dimension, the Shuttle was managed as a High- or even Medium-Tech program (assuming it would use off-the-shelf technologies), while it really required a Super-High-Tech style. Such style would allow an extended development period for testing alternative new technologies on a smallscale prototype, before selecting the optimal technology and freezing the final design.

A more recent example of the Diamond's power is Boeing's development project of its new 787 Dreamliner commercial aircraft. Based on a backlog of 900 orders, the company made a commitment to deliver its first commercial plane in 2008. Yet, the program has suffered more than three years delays and billions of Dollars cost overruns because the company did not assess correctly the difficulties it encountered later. One problem was the unexpected level of uncertainty introduced with the new technology of building the aircraft's body of composite materials. A second was the complexity of its wide network of suppliers to which the company delegated an unprecedented amount of design and development work. Using a Diamond Analysis would demonstrate that the program was initially managed as a Medium-Tech System project, while the preferred approach would require a High-Tech, Array style - see Fig. (4). In retrospect, the company had to add more design cycles and freeze the design much later than planned. There is no question that the 787 will eventually be a highly successful transporter, but Boeing could have saved much of the program's pain and embarrassment, had it assessed the real uncertainty and complexity prior to making the final commitment to its clients.

\section{INSPIRATIONAL LEADERSHIP}

The third component that strategic project leaders must address formally is leadership and inspiration. Great leaders are known for their ability to define and nurture a vision that energizes and brings out the best in people. Inspirational and visionary leaders are often transforming and inspiring their people to achieve outstanding results and to overcome enormous difficulties. Great leaders do not just exist at the national or chief executive levels. In fact, they could be found everywhere, including in great projects [9, 17]. However, how could we train project managers (who are often technical people) to become great and inspiring leaders? We therefore introduce the concept of project spirit that would become a formal component developed by managers in project planning and execution for the purpose of inspiration and motivation.

\section{Project Spirit - How to Inspire the Team}

Project managers could train themselves to become inspiring leaders and see this as part of their normal job. By building a deliberate and formal project spirit they should be able to translate company and business visions into great and exciting products, and build an environment that is based on energy, excitement, and enthusiasm, which will lead to successfully achieving the project's goal and creating the right competitive advantage and value. We define project spirit as: "The collective attitudes, emotions, and behavioral norms that are focused on the project's expected outcome and achievements" [17].

The first step in creating spirit is articulating an appropriate and exciting vision, which describes the goal or the product's advantage in an emotional way. Visions can often be summarized by a short motto or slogan, which will be derived form the strategy and articulate the result after the project is completed. Well-defined visions will excite the team, create meaning and unleash the energy in people. But they will also excite top management, and eventually influence the customer. All and all, the following four elements could help build a successful spirit.

- Vision - Building inspiration, excitement, and motivation

- $\quad$ Values - Directing and guiding the right behavior

- Symbols - Distinguishing the project's uniqueness in a tangible visible way

- $\quad$ Social Activity - Taking care of the fun and creating the team's bond

An older but excellent example of building a great project spirit was Digital Computer's Alpha Chip development in the 1980s [18]. The project created the world's fastest chip at that time, running three times quicker than its closest competitor. The team established a vision of "we can beat the world," and with enormous dedication and team was able to make the impossible. A more recent case is NASA's Kepler project, which was devoted to building and launching a spacecraft into the Milky Way in search for Earth-size extraterrestrial planets where other intelligent life may exist [15]. The project's visionary question of "are there others like us in the universe" has excited everyone on the team and beyond. The program's values were focused on good science, empowerment, and trust team members have in each other; it has built its own logos and slogans, and its team activity involved formal processes, combined with 


\section{Technology}

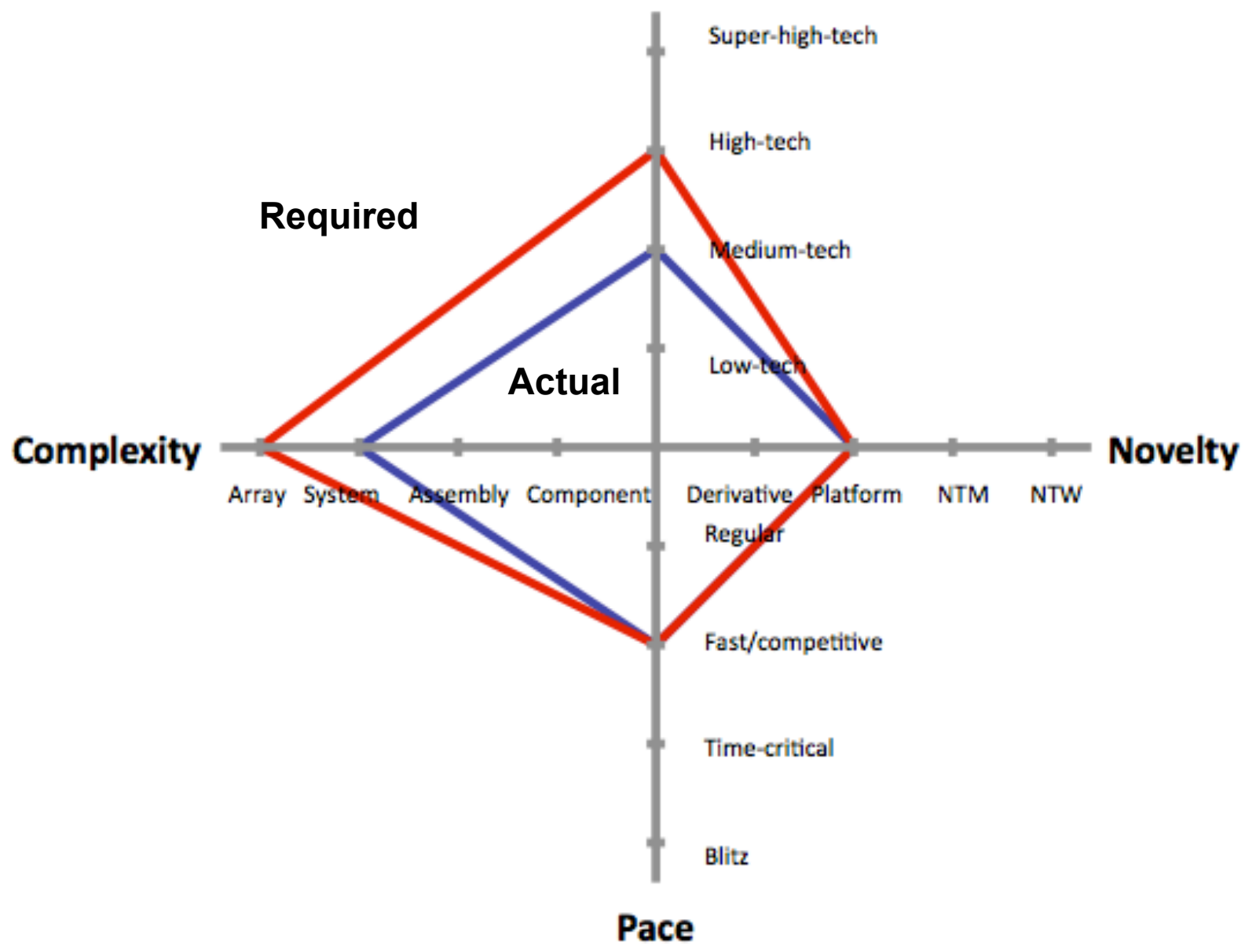

Actual PM Style

Dequired PM Style

Fig. (4). The diamond analysis of Boeing's 787 Dreamliner.

informal, inspirational, and energized meetings, celebrations, and picnics.

You may correctly think that not all project goals are as exciting as "building the world's fastest chip" or "looking for extraterrestrial life." Indeed, many projects are addressing regular business-related goals, internal improvement, or problem solving. Remember, however, that each project is doing something that was not done before - more important, its goal is to improve the world in some way. The vision part of a project spirit should articulate this goal in an emotional, nontechnical way. To illustrate such idea, here are a few visions taken from real projects in our research:

- "Free to kiss" - A project dedicated to developing a new vaccine for a contagious disease, which will be distributed to newly enrolled college students.

- "Beam of life" - A helmet torch for miners-rescue teams.

- "Less pain, more gain" - Streamlining customer service and maintenance operations at a large cableTV service provider.

\section{SUMMARY - PLANNING AND IMPLEMENTING STRATEGIC PROJECT LEADERSHIP ${ }^{\circledR}$}

\section{An Integrated Approach Concept - The Four Aspects}

Strategic Project leadership involves moving out of the current "get the job done" approach. While operational excellence is important, it must be accompanied by additional understanding. According to SPL, project managers and teams should learn to integrate four aspects during their work:

- Traditional On Time and Budget Delivery Meeting the project's efficiency goals of time and budget.

- $\quad$ Business Focus - Focusing the project on business results and competitive advantage/value.

- Dynamic Innovation - Adapting the project to context and specific level of innovation.

- Inspirational Leadership - Inspiration and motivating the project's team. 


\section{The Planning Framework - The Four Hierarchical Plans}

To guide the project's planning, SPL defines a hierarchy of four parts of a strategic project plan: Strategy, Innovation Spirit, Processes - see Fig. (2). A plan is designed to support the company's business strategy, but is unique to the project's specific business goals. Some of these plans will clearly include traditional components such as scope, WBS, CPM, etc., but they would be part of a larger framework of planning that starts with strategy, and moves down to the rest of the plans:

- $\quad$ Strategy - Building a unique project strategy to support the company's strategy and creating competitive advantage.

- Innovation - Identifying the specific level of innovation and context and dynamically adapting the specific project management style.

- $\quad$ Spirit - Creating a unique vision and a normative behavior environment that focus on the creation of competitive advantage.

- Processes - Building the project's traditional and strategic processes of planning and monitoring, and adapting them to the unique project characteristics.

\section{The Twelve Principles for Implementing Strategic Project Leadership ${ }^{\circledR}$}

The following principles summarize the rules that will help organizations and managers implement the SPL

approach and follow it through project execution. Although we did not discuss all principles in detail in this paper, the list provides a complete picture of what does SPL implementation require [19]:

1. Focus project management on business results; turn project managers into leaders, and make them responsible for the business results

2. Select your project (and program) portfolio based on different types of business objectives
3. Define a strategic charter for your project; obtain top management support upfront and throughout

4. Define why, (for) what, and how are you going to do the project

5. Set the expectations in advance, including the business results; define multiple success dimensions for different stakeholders

6. Define your project strategy, including the planned competitive advantage/value and strategic focus

7. Define your project's vision, and create the right spirit that will excite the team and support the creation of competitive advantage

8. Define your project organization and processes, and build a plan for project execution and monitoring, to ensure operational excellence, strategic focus, and inspiring leadership

9. Expect change - build hierarchical and dynamic plans; be ready to revise your plans as you move forward, obtain more information and remove uncertainty

10. Identify your project uniqueness and adapt your project management style based on the "Diamond" dimensions and other project characteristics

11. Conduct strategic project reviews, in which you reexamine the needs, the strategy, and the expectations, in addition to reviewing execution status and progress

12. Create an on-going learning organization within your project.

\section{CONCLUSION}

\section{Comparing The SPL Way to Traditional Project Management}

SPL is not replacing traditional project management. Instead, it is adding new components to address the needs of modern projects in today's dynamic and competitive world. The following Table $\mathbf{2}$ demonstrates the difference and the additional components. Notice that the SPL Way includes the traditional part.

Table 2. The evolution from traditional project management to Strategic Project Leadership ${ }^{\circledR}$.

\begin{tabular}{|c|c|c|}
\hline & Traditional Project Management & The Strategic Project Leadership ${ }^{\circledR}$ Way \\
\hline \hline Focus & Output & Outcome \\
\hline Project Goal & Delivering a Product on Time & Creating Value, Business Results and Benefits \\
\hline Managerial Thrust & Efficiency & Effectiveness, Efficiency \\
\hline Mindset & Operational & Strategic, Operational, Human \\
\hline PM Role & Get the Job Done & Dynamic, Adaptive Approach \\
\hline PM Style & One Size Fits All & Business Opportunity, Strategy, Competitive Advantage, Success Criteria, Project Type, Scope \\
\hline Project Definition & Project Scope & Needs, Strategy, Expectations, Progress \\
\hline Review & Progress, Milestones & Vision, Spirit, Motivation \\
\hline Human & Teams, Conflict & \\
\hline
\end{tabular}




\section{SUMMARY}

Moving toward a more strategic project management world is both timely and necessary. It is also possible. As we described, Strategic Project Leadership ${ }^{\circledR}$ provides an integrated framework to project management, with a clear goal of achieving business results by creating competitive advantage and value with the project. Implementing SPL in organizations may require changing the current paradigm of project management in the organization, and the most effective way to do it is should come from the top. Executives, who will adopt these realities earlier, will be tomorrow winners. The change will require cooperation between top management and project managers and teams, where executives entrust project leaders with higher autonomy and more power. However, even today's project leaders (formerly managers) could realize that they could do more by embracing these ideas into their current projects and understanding that just meeting time and budget goals is not enough.

\section{CONFLICT OF INTEREST}

The author confirms that this article content has no conflict of interest.

\section{ACKNOWLEDGEMENTS}

The Dynamic Adaptation studies were supported in part by grants from the DoD in Israel, and NASA.

The Strategic Project Leadership research was supported by grants from National Science Foundation (NSF Grant \# DMI 9812730), the Project Management Institute (PMI), and NASA. I greatly appreciate their support.

\section{REFERENCES}

[1] Project Management Institute. The Pulse of the Profession - Annual PMI Report. Newtown Square, PA: Project Management Institute 2013.
[2] Jugdev K, Muller R. A retrospective look at our evolving understanding of project success. Proj Manage J 2005; 36(4), 1931.

[3 Jamieson A, Morris PWG. Moving from corporate strategy to project strategy, In: Morris PWG, Pinto JK, Eds. The Wiley guide to managing projects. Hoboken, NJ: Wiley and Sons 2004; pp. 177205.

[4] Williams T. Assessing and moving on from the dominant project management discourse in the light of project overruns. IEEE Trans Eng Manag 2005; 52(4): 497-508.

[5] Lenfle S, Loch C. Lost roots: how project management came to emphasize control over flexibility and novelty. Calif Manage Rev 2009; 53(1): 32-55.

[6] Shenhar A, Dvir D. Reinventing project management: the diamond approach to successful growth and innovation. Boston, MA Harvard Business School Press 2007; p. 288.

[7] Cooke-Davies T. The "real" success factors in projects. Int J Proj Manage 2002; 20(3): 185-90.

[8] Baccarini, D. The logical framework method for defining project success. Proj Manag J 1999; 30(4): 25-32.

[9] Dvir D, Shenhar A. What great projects have in common. MIT Sloan Manag Rev 2011; 52(3): 19-21.

[10] Shenhar A, Dvir D, Levy O, Maltz A. Project success - a multidimensional, strategic concept. Long Range Planning 2001; 34: $18-22$.

[11] Shenhar A. The shuttle era: lasting lessons. Aviat Week Space Technol 2011; 18(25): 90.

[12] PMI. A guide to the project management body of knowledge. $5^{\text {th }}$ ed. Newton Square, PA: Project Management Institute 2013; p. 590 .

[13] Mintzberg H, Ahlstrand B, Lampel J. Strategy safari: a guided tour through the wilds of strategic management. New York: Simon \& Schuster 1998

[14] Patanakul P, Shenhar A. What project strategy really is: the fundamental building block in strategic project management. Proj Manag J 2012; 43(10): 4-20.

[15] Shenhar A, Dvir D, Milosevic D, et al. Toward a NASA-specific project management framework. Eng Manage J 2005; 17(4): 8-16.

[16] Shenhar A. One size does not fit all projects: exploring classical contingency domains. Manage Sci 2001; 47(3): 394-414.

[17] Aronson Z, Shenhar A, Reilly R. Project spirit: placing partakers' emotions, attitudes and norms in the context of project vision, artifacts, leader values, contextual performance and success. J High Technol Managem Res 2010; 21: 2-13.

[18] Katz R. How a team at digital equipment designed the 'alpha' chip. In: The human side of managing technological innovation. $2^{\text {nd }}$ ed Oxford University Press 2004

[19] Shenhar A, Dvir D, Thamhain MH. Linking project management with business strategy. Newtown Square, PA: Project Management Institute 2007; p. 239 